\title{
Structural and biophysical insights into the role of CD4 and CD8 in T cell activation
}

\author{
Yili Li ${ }^{1,2}$, Yiyuan Yin ${ }^{3}$ and Roy A. Mariuzza ${ }^{1,2 *}$ \\ ${ }^{1}$ W. M. Keck Laboratory for Structural Biology, Institute for Bioscience and Biotechnology Research, University of Maryland, Rockville, MD, USA \\ ${ }^{2}$ Department of Cell Biology and Molecular Genetics, University of Maryland, College Park, MD, USA \\ ${ }^{3}$ Department of Antibody Engineering, Genentech, South San Francisco, CA, USA
}

Edited by:

Bruno Laugel, Cardiff University, UK

Reviewed by:

Paula Kavathas, Yale University, USA

Cheng Zhu, Georgia Institute of

Technology, USA

Simon John Davis, University of

Oxford, UK

Rose Zamoyska, University of

Edinburgh, UK

*Correspondence:

Roy A. Mariuzza, Institute for Bioscience and Biotechnology

Research, University of Maryland, 9600 Gudelsky Drive, Rockville, MD

20850, USA

e-mail:rmariuzz@umd.edu
T cell receptors (TCRs) recognize peptides presented by $\mathrm{MHC}$ molecules (pMHC) on an antigen-presenting cell (APC) to discriminate foreign from self-antigens and initiate adaptive immune responses. In addition, $T$ cell activation generally requires binding of this same pMHC to a CD4 or CD8 co-receptor, resulting in assembly of a TCR-pMHC-CD4 or TCRpMHC-CD8 complex and recruitment of Lck via its association with the co-receptor. Here we review structural and biophysical studies of CD4 and CD8 interactions with $\mathrm{MHC}$ molecules and TCR-pMHC complexes. Crystal structures have been determined of CD8 $\alpha \alpha$ and $\mathrm{CD} 8 \alpha \beta$ in complex with MHC class I, of CD4 bound to MHC class II, and of a complete TCR-pMHC-CD4 ternary complex. Additionally, the binding of these co-receptors to pMHC and TCR-pMHC ligands has been investigated both in solution and in situ at the T cell-APC interface. Together, these studies have provided key insights into the role of CD4 and CD8 in T cell activation, and into how these co-receptors focus TCR on MHC to guide TCR docking on $\mathrm{pMHC}$ during thymic $\mathrm{T}$ cell selection.

Keywords: CD4, CD8, MHC, $\mathrm{T}$ cell receptor, structure, $\mathrm{T}$ cell activation

\section{INTRODUCTION}

Adaptive immunity depends on specific recognition by an $\alpha \beta \mathrm{T}$ cell receptor (TCR) of an antigenic peptide bound to a major histocompatibility complex (pMHC) molecule on an antigenpresenting cell (APC). However, TCR-pMHC interactions alone do not efficiently trigger $\mathrm{T}$ cells, requiring the participation of the co-receptors CD4 and CD8 (1-4). These transmembrane glycoproteins mark different $\mathrm{T}$ cell subsets. CD4 is expressed on Th1, Th2, and Th17 helper cells, as well as on CD4 regulatory T cells (Tregs); CD8 is expressed on cytotoxic T lymphocytes (CTLs) and CD8 Tregs. CD4 and CD8 enhance $\mathrm{T}$ cell signaling by binding MHC class II (CD4) or MHC class I (CD8) molecules on APCs. The interaction of CD4 with MHC class II greatly reduces the number of antigenic peptides required for $\mathrm{T}$ cell activation (5) and substantially increases cytokine production by helper $\mathrm{T}$ cells (1). Likewise, the CD8-MHC class I interaction enhances the antigen sensitivity and response of cytotoxic T cells to pMHC ligands (6).

The principal role of the CD4 and CD8 co-receptors is to recruit the Src tyrosine kinase p65lck (Lck) to the TCR-pMHC complex following co-receptor binding to $\mathrm{MHC}$, resulting in assembly of a TCR-pMHC-CD4 or TCR-pMHC-CD8 ternary complex (7-10). Recruitment of Lck occurs via its association with the cytoplasmic tail of CD4 or CD8. The accompanying increase in the local concentration of Lck promotes phosphorylation of immunoreceptor tyrosine activation motifs (ITAMs) in the cytoplasmic tails of CD3 subunits associated with the TCR in the TCR-CD3 complex, leading to the recruitment and activation of Zap-70. Activated Zap-70 phosphorylates LAT and SLP-76, which function as scaffolds to recruit other signaling molecules to the downstream $\mathrm{T}$ cell signaling apparatus that regulates $\mathrm{T}$ cell activation, proliferation, and differentiation. The targeted delivery of Lck to TCR by CD4 or CD8 during thymic selection is believed to impose MHC restriction on the developing $\alpha \beta$ TCR repertoire (11). In support of this idea, $\alpha \beta$ TCRs in mice lacking co-receptors and MHC are not biased toward pMHC ligands, but instead display antibody-like recognition specificities $(12,13)$.

This review focuses on structural and biophysical studies of CD4 and CD8 interactions with MHC molecules. Crystal structures have been determined of $\mathrm{CD} 8 \alpha \alpha$ and $\mathrm{CD} 8 \alpha \beta$ in complex with MHC class I, of CD4 bound to MHC class II, and, most recently, of a complete TCR-pMHC-CD4 ternary complex. In addition, the binding of these co-receptors to pMHC and TCR-pMHC ligands has been investigated both in solution and in situ. Collectively, these studies have provided critical insights into the role of CD4 and CD8 in T cell activation and in guiding TCR docking on pMHC during $\mathrm{T}$ cell development.

\section{INTERACTION OF CD8 WITH MHC CLASS I}

CD8 exists as two isoforms, $\mathrm{CD} 8 \alpha \alpha$ and $\mathrm{CD} 8 \alpha \beta$, which are expressed on different cell types and appear to have different functions. CD8 $\beta \beta$ homodimers have also been reported, but these lack MHC-binding activity and their significance is unknown (14). Whereas CD8 $\alpha \alpha$ is found on $\gamma \delta \mathrm{T}$ cells, intestinal intraepithelial T lymphocytes, and natural killer (NK) cells, $\mathrm{CD} 8 \alpha \beta$ is expressed on $\alpha \beta$ TCR thymocytes and CTLs. The function of CD8 $\alpha \alpha$ remains obscure, but it has been implicated in the negative regulation of intestinal intraepithelial $\mathrm{T}$ lymphocytes (15). By contrast, $\mathrm{CD} 8 \alpha \beta$ is clearly required for positive selection of $\mathrm{CD}^{+} \mathrm{T}$ cells in the thymus (16-18) and for activation of $\mathrm{CD}^{+} \mathrm{T}$ cells in the periphery (19). In both $C D 8 \alpha \alpha$ and $C D 8 \alpha \beta$, Lck associates with the CD $8 \alpha$ 
chain. In addition, ligation of $\mathrm{CD} 8 \alpha \beta$ by $\mathrm{MHC}$, in the absence of TCR engagement, results in apoptosis of a proportion of doublepositive thymocytes, which may be a mechanism for removing thymocytes that have failed positive selection (20).

Fluorescence resonance energy transfer experiments have shown that, during $\mathrm{T}$ cell activation, the TCR binds initially to pMHC, and that CD8 then binds to the same pMHC as the TCR, leading to formation of a TCR-pMHC-CD8 complex (21). This order of engagement ensures that the specific TCR-pMHC interaction dominates $\mathrm{T}$ cell recognition. As measured by surface plasmon resonance (SPR), CD8 binds very weakly to MHC class I in both mouse and human, with little influence of the MHC-bound peptide (21-23). In the mouse, the average binding affinity for CD8 $\alpha \beta$ $\left(K_{\mathrm{D}} \sim 50 \mu \mathrm{M}\right)$ is similar to that for CD8 $\alpha \alpha(\sim 70 \mu \mathrm{M})$, with some variation depending on the particular MHC class I allele. The human CD8-MHC class I interaction is weaker still, averaging $\sim 150 \mu \mathrm{M}$ (24-26). In both cases, these affinities are 10- to 100-fold lower than for most TCR-pMHC interactions.

In overall agreement with these SPR results, in situ measurements of the mouse CD8-MHC class I interaction gave an affinity several orders of magnitude lower than that of TCR for pMHC (27). These experiments used a micropipette adhesion frequency assay to measure the adhesion kinetics of live $\mathrm{T}$ cells interacting with pMHC ligands presented on surrogate APCs. The twodimensional (2D) binding parameters derived from this technique are thought to more accurately reflect biological interactions in membranes than the three-dimensional (3D) parameters derived from SPR, in which fluid-phase receptors and ligands are removed from their cellular environment (28).

Although the affinity of CD8 for MHC class I is weak, recent $2 \mathrm{D}$ affinity measurements support the idea that CD8 contributes significantly to stabilizing the TCR-pMHC interaction at the T cell-APC interface (9). These experiments revealed that the TCRpMHC-CD8 trimolecular interaction generates synergy over the simple sum of the individual TCR-pMHC and pMHC-CD8 interactions, and that this cooperativity amplifies peptide discrimination. Thus, in addition to its primary role of recruiting Lck to the TCR-pMHC complex, a secondary function of CD8 is to reinforce TCR binding to the pMHC ligand. Whether the $\mathrm{CD} 4$ co-receptor also promotes cooperative binding remains to be determined.

The micropipette adhesion frequency assay also revealed that the kinetics of the TCR-pMHC-CD8 trimolecular interaction at the $\mathrm{T}$ cell membrane proceeds in two stages (9). The first consists of TCR-dominant binding to agonist pMHC. This triggers a second stage involving an upregulation of CD8-dependent adhesion after a $1 \mathrm{~s}$ delay. The second stage requires Lck kinase activity to initiate CD8 binding to the same pMHC ligand engaged by the TCR, generating synergy. It remains to be established whether the TCR-pMHC-CD4 trimolecular interaction involves a similar sequence of events.

\section{STRUCTURES OF CD8 BOUND TO MHC CLASS I}

$\mathrm{CD} 8 \alpha \beta$ is a heterodimeric type I transmembrane glycoprotein, whose $\alpha$ and $\beta$ chains are each composed of an immunoglobulin (Ig)-like domain connected by a long stalk to a transmembrane domain and a cytoplasmic tail, with Lck bound to the CD8 $\alpha$ tail.
By contrast, the CD $8 \alpha \alpha$ homodimer comprises only the $\alpha$ chain. Four structures of CD8 $\alpha \alpha$ or $\mathrm{CD} 8 \alpha \beta$ bound to MHC class I molecules have been reported: (1) the complex between human $\mathrm{CD} \alpha \alpha$ and HLA-A*0201 (29); (2) the complex between human CD8 $\alpha \alpha$ and HLA-A*2402 (30); (3) the complex between mouse CD8 $\alpha \alpha$ and $\mathrm{H}-2 \mathrm{~K}^{\mathrm{b}}(31)$; and (4) the complex between mouse $\mathrm{CD} 8 \alpha \beta$ and $\mathrm{H}-2 \mathrm{D}^{\mathrm{d}}(23)$.

In the $\mathrm{CD} 8 \alpha \beta-\mathrm{H}-2 \mathrm{D}^{\mathrm{d}}$ complex (23), the $\mathrm{CD} 8 \alpha \beta$ heterodimer contacts only the $\alpha 3$ domain of the MHC class I heavy chain (Figure 1A). By contrast, CD8 $\alpha \alpha$ also contacts the $\alpha 2$ domain and $\beta_{2}$-microglobulin $\left(\beta_{2} \mathrm{~m}\right)$ in the CD $\alpha \alpha-H L A-A^{*} 0201$ (29), CD8 $\alpha \alpha-$ HLA-A $2402(30)$, and CD8 $\alpha \alpha-\mathrm{H}-2 \mathrm{~K}^{\mathrm{b}}$ complexes (31) (Figure 1C). The CD8 $\beta$ subunit occupies a position equivalent to that of the CD8 $\alpha 1$ subunit in the three CD $8 \alpha \alpha-M H C$ class I structures, which places CD8 $\beta$ proximal to the T cell membrane. The $C D 8 \alpha$ subunit of $C D 8 \alpha \beta$ is located in the same position as the $\mathrm{CD} 8 \alpha 2$ subunit, distal from the $\mathrm{T}$ cell and near the $\mathrm{C}$-terminus of the MHC class I $\alpha 3$ domain (Figures 1A,C). Nearly all MHC class I residues that mediate key interactions with $\mathrm{CD} 8 \alpha \alpha$ or $\mathrm{CD} 8 \alpha \beta$ are non-polymorphic, which explains the largely allele-independent nature of CD8 binding.

For both $\mathrm{CD} 8 \alpha \alpha$ and $\operatorname{CD} 8 \alpha \beta$, the main binding interaction is with a protruding loop in the $\alpha 3$ domain of the MHC class I molecule (CD loop), corresponding to residues 220-228 (Figures 1B,D). This loop is flexible in the absence of CD8, but is stabilized by $\mathrm{CD} 8$ binding. In the CD $8 \alpha \alpha-\mathrm{MHC}$ class I structures, the two CDR3-like loops of the CD8 $\alpha$ subunits clamp onto the central $\beta$-turn portion of the CD loop in an antibody-like manner, as do the two CDR3-like loops of $\operatorname{CD} 8 \alpha \beta(23,29-31)$. In addition, CD $8 \alpha \alpha$ contacts the $\alpha 2$ domain and $\beta_{2}$ m through its CD $8 \alpha 1$ subunit, whereas the corresponding $C D 8 \beta$ subunit of $C D 8 \alpha \beta$ contacts only $\alpha 3$. Of particular note in the CD $8 \alpha \beta-H-2 D^{d}$ complex is Gln226 of H-2D ${ }^{\mathrm{d}}$, a highly conserved residue among MHC class I alleles and the only one that interacts with both CD8 $\alpha$ and CD8 $\beta$ (Figure 1B).

\section{ROLE OF THE CD8 STALK REGION IN CO-RECEPTOR FUNCTION}

The Ig-like domains of $\mathrm{CD} 8 \alpha$ and $\mathrm{CD} 8 \beta$ are tethered to the $\mathrm{T}$ cell membrane by long stalk regions comprising $\sim 45$ residues for CD8 $\alpha$ and $\sim 35$ residues CD8 $\beta$ (32). These stalk regions, which are rich in threonine, serine, and proline residues, are heavily $O$ glycosylated at multiple sites in all species studied (33). The stalk of $\mathrm{CD} 8 \alpha \beta$ undergoes developmentally programed $O$-glycan modification controlled by the sialyltransferase ST3 Gal-I, which catalyzes addition of sialic acid to core $1 O$-linked glycans (34). In particular, immature $\mathrm{CD} 4{ }^{+} \mathrm{CD} 8{ }^{+}$thymocytes exhibit lower levels of CD8 sialylation than mature thymocytes $(32,34,35)$. Decreased sialylation of the $C D 8 \alpha \beta$ stalk was found to markedly increase the affinity of CD8 for MHC class I, as measured by MHC tetramer binding, thereby affecting $\mathrm{T}$ cell selection $(34,35)$. Enhanced $\mathrm{CD} 8 \alpha \beta$ binding at the $\mathrm{CD} 4{ }^{+} \mathrm{CD} 8{ }^{+}$stage facilitates elimination of autoreactive $\mathrm{T}$ cells in the thymus. However, once a double-positive thymocyte has differentiated to the $\mathrm{CD}^{+}$stage, $\mathrm{O}$-glycan sialylation of the $\mathrm{CD} 8 \alpha \beta$ stalk reduces co-receptor affinity for $\mathrm{pMHC}$, requiring a stronger TCR-pMHC interaction for T cell activation in the periphery $(34,35)$. 


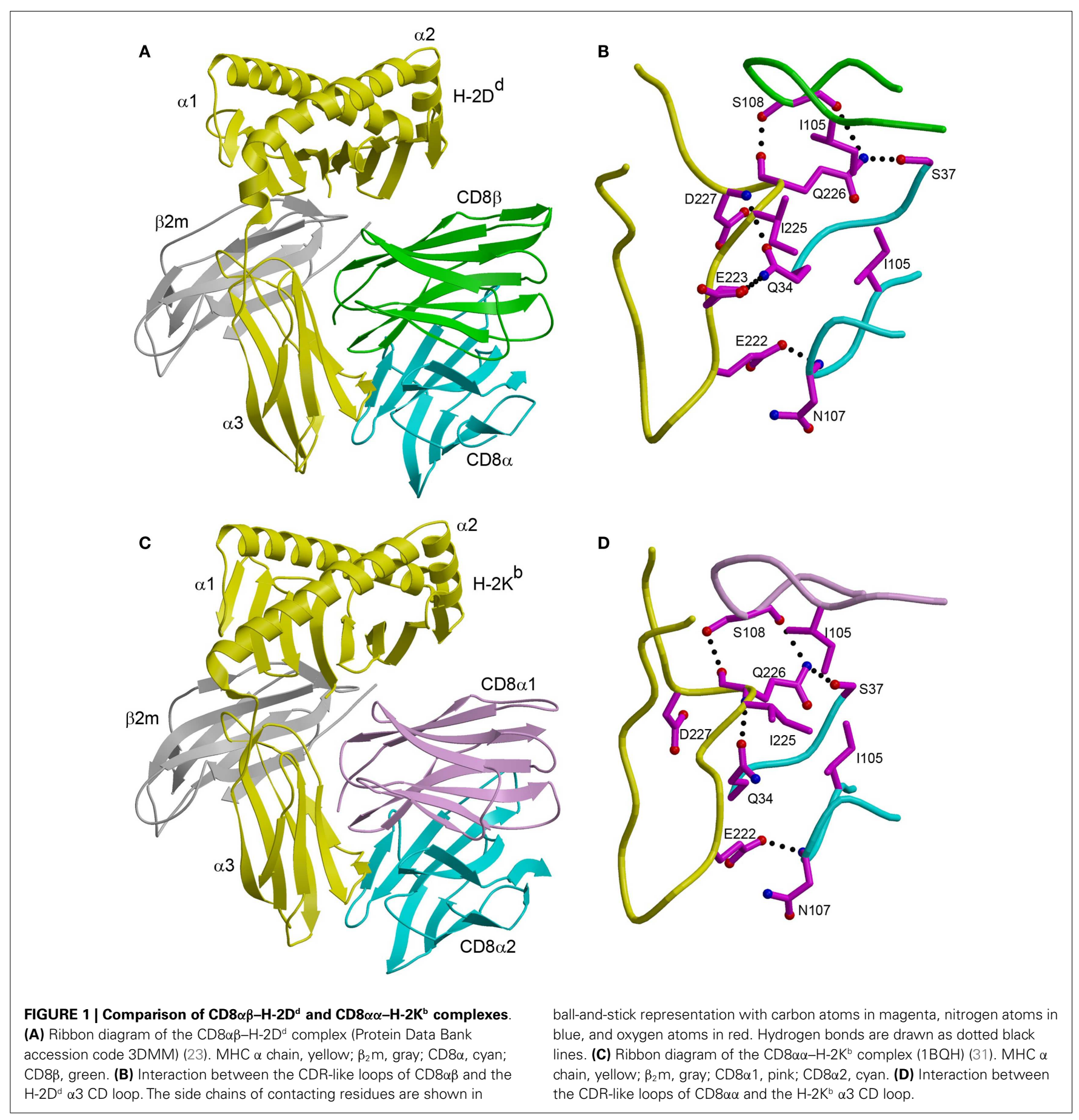

The structural basis for reduced $\mathrm{CD} 8 \alpha \beta$ affinity for MHC class I upon sialylation of the stalk region is unknown. One possibility is that sialylation alters the association or orientation of the Ig-like domains of the $\mathrm{CD} 8 \alpha \beta$ heterodimer, reducing its capacity to bind MHC class I (34). However, Merry et al. (36) found that sialylation had little or no effect on the overall structure of CD8, insofar as sialylated and non-sialylated forms of soluble CD8 $\alpha \alpha$ exhibited indistinguishable hydrodynamic properties. This suggests that the results of Moody et al. (34) and Daniels et al. (35) might be explained by avidity effects arising from aggregation of unsialylated CD8 on the T cell surface that increase MHC tetramer binding (36).

Irrespective of the underlying mechanism, the finding that developmentally regulated glycosylation of the CD8 $\alpha \beta$ stalk can modulate MHC binding at the cell surface demonstrates that the stalk has a specialized role in co-receptor function, beyond simply attaching the MHC-binding domains to the T cell membrane. The long $\mathrm{CD} 8 \alpha \beta$ stalk may also allow a possible cis interaction 
between CD8 and MHC class I expressed on the same T cell (37), in addition to the established trans interaction between CD8 and MHC class I expressed on different cells. Interestingly, the stalk regions of other immune system receptors have also been recently found to play prominent roles in receptor function. For example, the long stalk regions of Ly $49 \mathrm{NK}$ cell receptors enable binding to MHC class I in cis or trans configurations (38). Additionally, the stalk domain of the activating NK receptor NKp30 is critical for NK cell killing and may contribute directly to binding its tumor cell ligand B7-H6 (39).

No 3D structural information is available for the stalk regions of $\mathrm{CD} 8 \alpha \beta$ or $\mathrm{CD} 8 \alpha \alpha$, since the stalks, when included in the constructs used for protein expression, were mostly or entirely disordered in the CD8-MHC class I crystal structures (23, 29-31). Although this has been interpreted to mean that that the CD8 stalk is highly flexible, it should be emphasized that the stalks completely lacked glycosylation because the CD8 proteins were produced in bacteria. However, there is biophysical evidence that $O$-glycosylation may significantly restrict the flexibility of the stalks. Studies of mucins have demonstrated that $O$-glycans stiffen polypeptides through steric interactions between peptide-linked $N$-acetylgalactosamine residues and adjacent peptide residues $(40,41)$. Moreover, $O$ glycans in the CD8 stalk polypeptides were found to reduce the overall extension of the stalk from a theoretical maximum of $3.4 \AA$ per residue to $2.6 \AA$ per residue, indicating rigidification $(36,42)$. Therefore, $O$-glycosylation may limit the mobility of the CD8 head group relative to the $\mathrm{T}$ cell membrane, an important consideration in evaluating co-receptor interactions with TCR-pMHC during thymic selection and peripheral antigen recognition, as discussed below.

\section{STRUCTURES OF CD4 BOUND TO MHC CLASS II}

CD4 is a monomeric type I transmembrane glycoprotein consisting of four Ig-like extracellular domains connected by a short stalk to a transmembrane domain and a cytoplasmic tail that interacts with Lck. CD4 binds MHC class II with exceptionally low affinity compared to all other leukocyte cell-cell recognition molecules characterized to date, whose $K_{\mathrm{D}}$ s typically fall in the $1-100 \mu \mathrm{M}$ range, as measured by $\operatorname{SPR}(43,44)$. For the CD4-MHC class II interaction, $K_{\mathrm{D}}$ s have been estimated to range from $\sim 200 \mu \mathrm{M}$ (for human CD4 binding to mouse MHC class II) (45) to $>2 \mathrm{mM}$ (for human CD4 binding to human MHC class II) (43). These affinities are substantially weaker than those for CD8-MHC class I interactions, which range from $\sim 10 \mu \mathrm{M}$ (for mouse $\mathrm{CD} 8 \alpha \beta$ binding to H-2D ${ }^{\mathrm{d}}$ ) (23) to $\sim 150 \mu \mathrm{M}$ (for human CD8 $\alpha \alpha$ binding to HLA$\left.A^{*} 0201\right)$ (26). Presumably, evolution has calibrated the affinity of CD4 for MHC class II to enable peripheral T cells to respond efficiently to the very low abundance of foreign pMHC molecules on APCs (sensitivity), yet avoid activation by the far greater number of self-pMHC molecules (discrimination), which could cause autoimmunity.

The ability of CD4 to recognize highly polymorphic MHC class II molecules is central to its function as a co-receptor (1). In humans, MHC class II molecules are encoded by three separate loci (HLA-DR, -DQ, and -DP), while in mice they are encoded by two loci (I-A and I-E). For HLA-DR, most variability derives from the $\beta$-chain, with $>700$ known alleles at the population level, whereas there are only three $\alpha$-chain variants. In contrast, both $\alpha$ - and $\beta$-chains of HLA-DQ and -DP are polymorphic (46). Two structures of CD4 bound to MHC class II molecules have been reported: (1) the complex between human CD4 (domains D1 and D2) and mouse I-A ${ }^{\mathrm{k}}$ to $4.3 \AA$ resolution (47); and (2) the complex between human CD4 (domains D1 and D2) and human HLADR1 to $2.4 \AA$ resolution (48). These structures readily explain the ability of CD4 to recognize multiple MHC class II alleles.

The CD4-I-A ${ }^{\mathrm{k}}$ and CD4-HLA-DR1 complexes display similar overall topologies, although only the higher-resolution CD4HLA-DR1 structure permitted an atomic-level description of the CD4-MHC class II interface. In both complexes, CD4 binds MHC class II through its membrane-distal D1 domain, which contacts the membrane-proximal $\alpha 2$ and $\beta 2$ domains of the MHC class II molecule (Figure 2A). CD4 uses two discontinuous regions to engage MHC class II in a concavity formed by the $\alpha 2$ and $\beta 2$ domains (Figure 2B). The first region, composed of $\beta$-strands $C^{\prime}$ and $C^{\prime \prime}$, exclusively contacts the $\beta 2$ domain. The second region, comprising a short $3{ }_{10}$ helix within the loop connecting $\beta$-strands $\mathrm{D}$ and $\mathrm{E}$, binds solely to the $\alpha 2$ domain.

Figure 2C shows sequence alignments of the $\alpha$ - and $\beta$-chains of selected HLA-DR, -DP, and -DQ alleles in the regions where HLADR1 contacts CD4. For the $\beta$-chains, 11 of 12 CD4-contacting residues are absolutely conserved in these human MHC class II molecules, and 1 is conservatively substituted (Val116Ile in HLA$D Q$ ). For the $\alpha$-chains, all three CD4-contacting residues (Glu88, Thr90, Leu176) are invariant across human MHC class II alleles. Hence, the remarkable cross-reactivity of CD4 is attributable to the targeting of non-polymorphic residues in the concavity formed by the $\alpha 2$ and $\beta 2$ domains of HLA-DR, -DP, and -DQ. For I-A ${ }^{\mathrm{k}}, 11$ of $14 \mathrm{CD} 4$-contacting residues are identical to those of HLA-DR1, while for $\mathrm{I}^{\mathrm{k}} \mathrm{E}^{\mathrm{k}} 12$ of 14 are identical (Figure 2C). All non-identical residues are conservatively substituted in both molecules. Therefore, CD4 almost certainly engages all human and mouse MHC class II molecules in the same manner as it does HLA-DR (48).

\section{STRUCTURE OF A TCR-pMHC-CD4 TERNARY COMPLEX}

The low affinity of CD4 for MHC class II presented a major technical obstacle to crystallizing a TCR-pMHC-CD4 ternary complex. To overcome this obstacle, in vitro directed evolution by yeast surface display was used to increase the affinity of CD4 for MHC class II (49). Affinity maturation by yeast display relies on expression of a library of mutants on the surface of yeast, followed by selection of variants with improved affinity (50). The D1 domain of human CD4 was subjected to in vitro random mutagenesis, and the resulting mutant library was displayed on yeast by fusion to agglutinin protein Aga2p (48). Because CD4 binds MHC class II very weakly $(43,45)$, the CD4 library was sorted by flow cytometry using HLA-DR1 tetramers, rather than monomers, to increase the avidity of the selecting ligand. In this way, a CD4 mutant that bound HLA-DR1 with $K_{\mathrm{D}}=9 \mu \mathrm{M}$ was isolated, compared with no detectable binding for wild-type CD4, even at high concentrations $(400 \mu \mathrm{M})$. The CD4 mutant exhibited similar affinity for HLA-DR4 $\left(K_{\mathrm{D}}=10 \mu \mathrm{M}\right)$, in agreement with the ability of CD4 to recognize all HLA-DR alleles, as discussed above.

The affinity-matured CD4 mutant contained two substitutions in the D1 domain: Gln40Tyr and Thr45Trp. In the mutant 


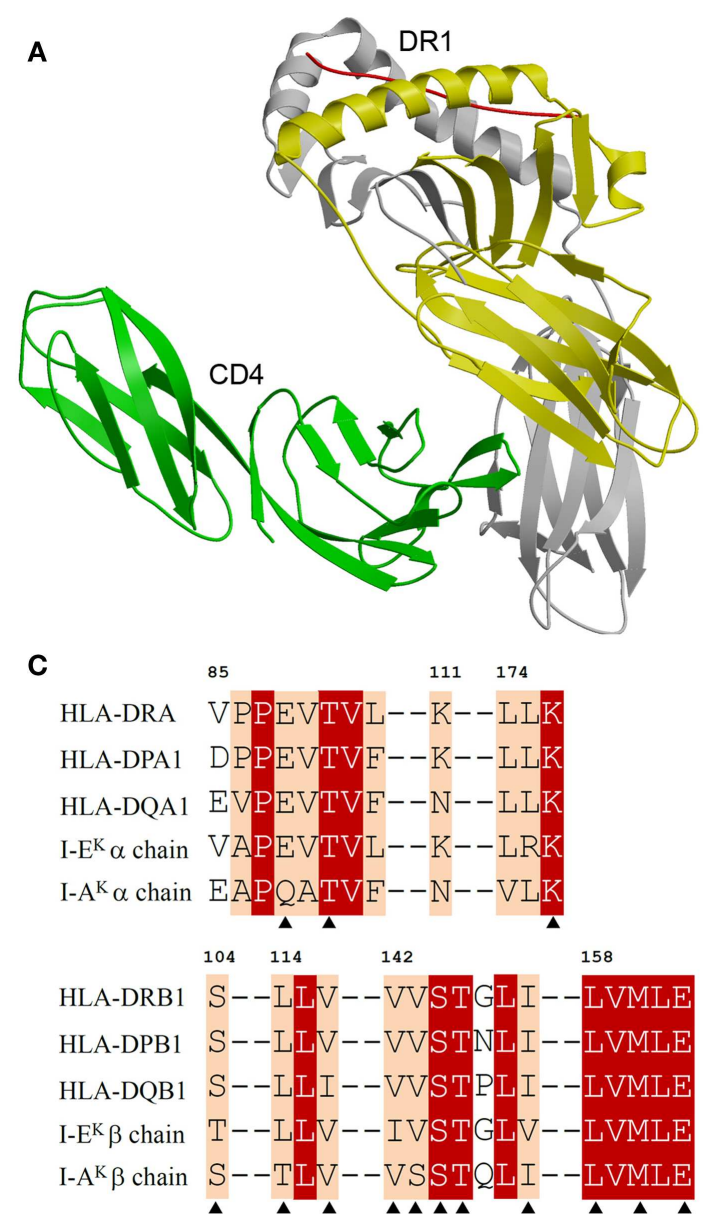

FIGURE 2 | Structure of a human CD4-MHC class II complex. (A) CD4 (green) contacts the $\alpha 2$ (yellow) and $\beta 2$ (gray) domains of HLA-DR1 through its D4 domain (3S4S) (48). The MHC-bound peptide is red. (B) The CD4-HLA-DR1 binding interface. The two regions of CD4 (residues 35-48 and 59-63) that contact HLA-DR1 are shown in stick representation with carbon atoms in green, oxygen atoms in red, and nitrogen atoms in blue. The molecular surface of HLA-DR1 that interacts with CD4 is depicted with the $\alpha 2$ domain in yellow and the $\beta 2$ domain in gray. (C) Sequence alignment of the CD4-contacting regions of the $\alpha$ - and $\beta$-chains of different human and mouse MHC class II alleles. Residues that contact CD4 in the

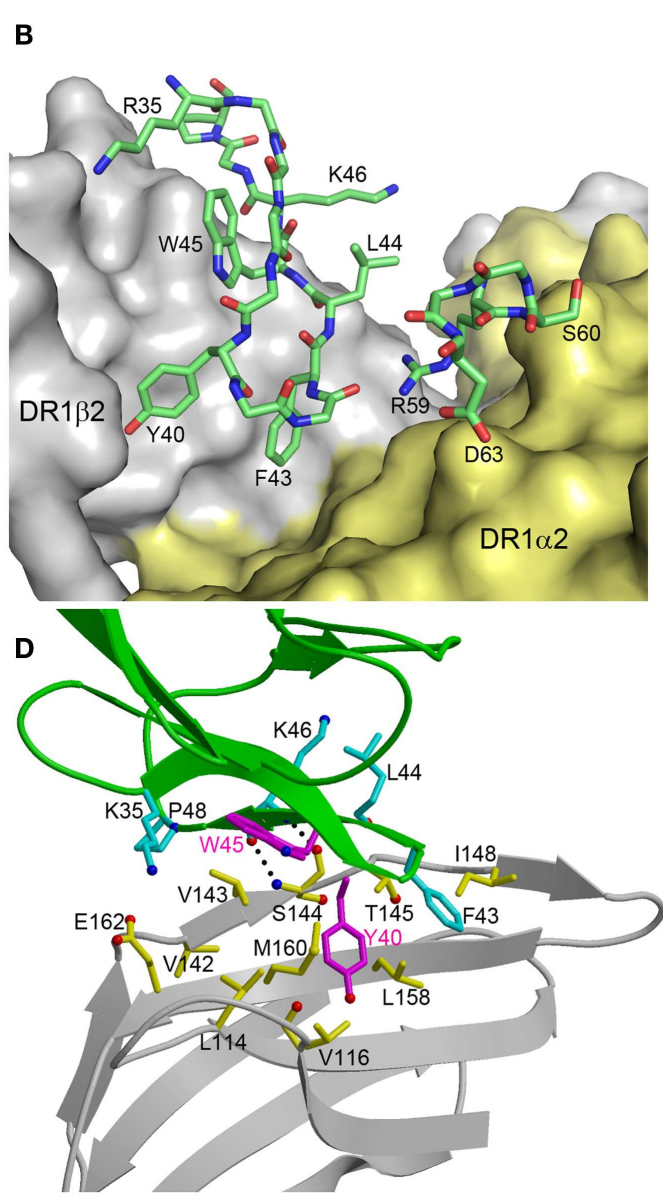

CD4-HLA-DR1 structure are marked with triangles. White characters on a red background show residues that are strictly conserved across human or mouse MHC class II molecules. Black characters on a tan background are conservatively substituted residues. (D) Close-up view of the interactions between an affinity-matured CD4 mutant (green) and the HLA-DR1 $\beta 2$ domain (gray). The side chains of interacting residues are shown in ball-and-stick representation with carbon atoms in cyan (CD4) or yellow (HLA-DR1), oxygen atoms in red, and nitrogen atoms in blue. The mutated Tyr40 and Trp45 residues of CD4 are in magenta. Hydrogen bonds are drawn as dotted black lines.
CD4-HLA-DR1 structure (48), CD4 Trp45 is located at the center of the interface with HLA-DR1, where its bulky side chain makes multiple hydrophobic contacts with DR1 $\beta 2$ Val143 (Figure 2D). Similarly, CD4 Tyr40 is surrounded by apolar DR1 $\beta 2$ residues Leu114, Val116, Leu158, and Met160, resulting in increased hydrophobic interactions at the mutation site. Together, the Gln40Tyr and Thr45Trp mutations improved shape and chemical complementarity with HLA-DR1, thereby stabilizing the CD4-HLA-DR1 complex.

The enhanced affinity of this CD4 mutant made possible the crystallization and structure determination of a complete TCR-pMHC-CD4 ternary complex involving a human autoimmune TCR (MS2-3C8), a self-peptide from myelin basic protein (MBP) bound to HLA-DR4, and CD4 (49) (Figure 3A).
The TCR-pMHC-CD4 complex resembles a pointed arch in which both TCR and CD4 are tilted rather than oriented vertically. The TCR and CD4 molecules each make an angle of $\sim 65^{\circ}$ with the $\mathrm{T}$ cell surface. The apex of the arch is formed by the $\alpha 2$ and $\beta 2$ domains of HLA-DR4 and the D1 domain of CD4. MS2-3C8 engages MBP via the canonical docking mode of $\alpha \beta$ TCRs (51), in which the TCR adopts a central diagonal orientation over pMHC $(52,53)$. There are no direct contacts between TCR and CD4 (Figure 3A), in agreement with an earlier prediction (47).

The CD4 molecule bound to TCR-pMHC retains the overall extended conformation observed in different crystal forms of unbound CD4 (54), with some hinge-like variability at the D2-D3 junction. The limited segmental flexibility of CD4 implies that any 


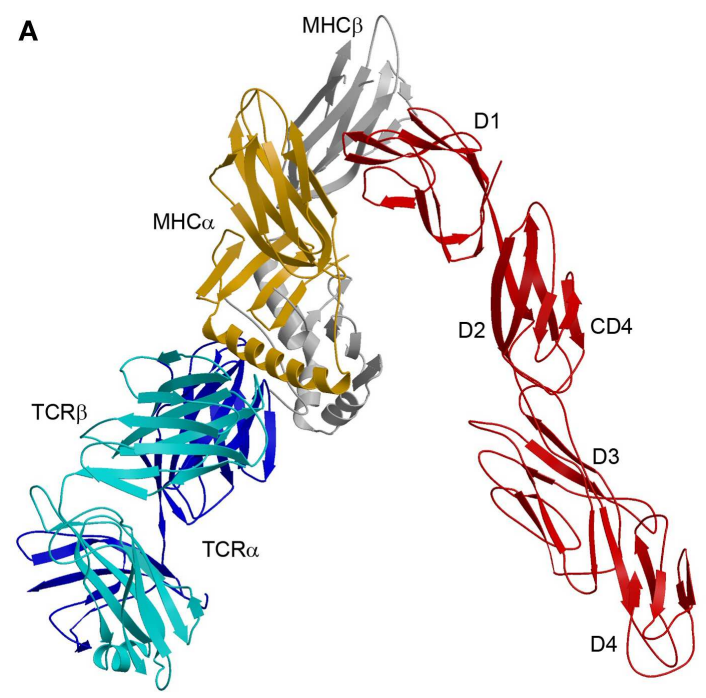

FIGURE 3 | Comparison of TCR-pMHC-CD4 and TCR-pMHC-CD8 ternary complexes. (A) Crystal structure of a TCR-pMHC-CD4 complex (MS2-3C8-MBP-DR4-CD4) oriented as if the TCR and CD4 molecules are attached to the T cell at the bottom and the MHC class II molecules is attached to an opposing APC at the top (3TOE) (49). TCR $\alpha$ chain, blue; TCR $\beta$ chain, cyan; $\mathrm{MHC} \alpha$ chain, yellow; $\mathrm{MHC} \beta$ chain, gray; CD4, red. (B) Hypothetical model of the TCR-pMHC-CD8 complex. The model was

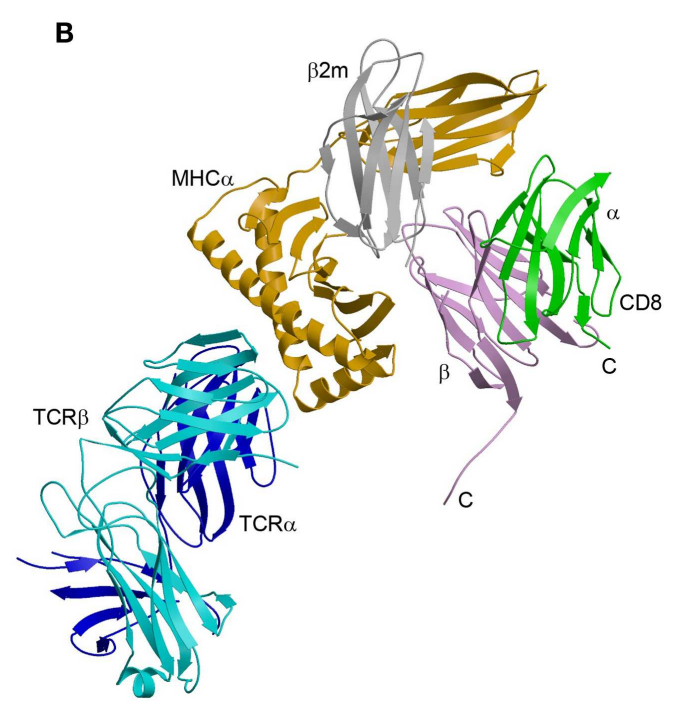

constructed by superposing the CD $8 \alpha \beta-\mathrm{H}-2 \mathrm{D}^{\mathrm{d}}$ complex (3DMM) (23) onto a $\mathrm{TCR}-\mathrm{H}-2 \mathrm{D}^{\mathrm{b}}$ complex (3POY) through the $\mathrm{MHC}$ class I molecule. A portion of the $C D 8 \beta$ stalk region was visible in the crystal structure and points toward the $T$ cell membrane. The $\mathrm{C}$-termini of the CD8 $\alpha$ and $\mathrm{CD} 8 \beta$ chains are labeled. The orientation of the TCR-pMHC complex is the same as in (A). TCR $\alpha$ chain, blue; TCR $\beta$ chain, cyan; MHC $\alpha$ chain, yellow; $\beta_{2} m$, gray; CD $8 \alpha$, green; CD8 $\beta$, violet. significant variations in overall complex architecture must arise from differences in TCR docking on $\mathrm{pMHC}$.

The absence of direct contacts between TCR and CD4 explains how these molecules can simultaneously, yet independently, bind to pMHC. Importantly, the wide separation $(\sim 70 \AA)$ between the membrane-proximal TCR $\mathrm{C} \alpha / \mathrm{C} \beta$ module and CD4 D4 domain provides ample room for the placement of TCR-associated CD $3 \varepsilon \gamma$, $\varepsilon \delta$, and $\zeta \zeta$ subunits (Figure 4A), which transmit activation signals to the T cell (55). Although no crystal structure is available for the TCR-CD3 complex, mutational studies have identified docking sites for the ectodomains of $\mathrm{CD} 3 \varepsilon \delta$ and $\mathrm{CD} 3 \varepsilon \gamma$, which interact with the TCR through adjacent $\mathrm{C} \alpha \mathrm{DE}$ and $\mathrm{C} \beta \mathrm{CC}^{\prime}$ loops, respectively (56-58). Based on this information, CD3 $\varepsilon \gamma$ and CD $3 \varepsilon \delta$ would be situated inside the TCR-pMHC-CD4 arch, wedged between the TCR and T cell membrane (Figure 4A). In the organization of the TCR-CD3 complex proposed by Fernandes et al. (58), only $\mathrm{CD} 3 \gamma$ and $\mathrm{CD} 3 \delta$ contact the TCR, whereas CD $3 \varepsilon$ projects away from the receptor. The relative proximity of $\mathrm{CD} 3 \varepsilon$ to $\mathrm{CD} 4$ in the TCR-pMHC-CD4 complex, compared to CD3 $\gamma$ or CD3 $\delta$, may confer preference to $\mathrm{CD} 3 \varepsilon$ in the ITAM phosphorylation cascade upon Lck recruitment by CD4 (Figure 4A).

The ectodomain of $\mathrm{CD} 3 \zeta$, which is only nine amino acids in length, has not been implicated in interactions with the TCR ectodomain, and so is not shown in Figure 4A. However, mutational analysis of the transmembrane regions of TCR and CD3 subunits has established that $\mathrm{CD} 3 \zeta \zeta$ is associated with $\mathrm{TCR} \alpha$ in the T cell membrane (59).

It has been proposed that, in resting $\mathrm{T}$ cells, CD $3 \varepsilon$ ITAMs are sequestered in the membrane, and that activation results in ITAM exposure to Src kinases (60). If so, the TCR-pMHC-CD4 structure suggests a possible mechanism by which this may occur. If the TCR shifts from an upright to a tilted orientation upon formation of the TCR-pMHC-CD4 complex (Figure 3A), this movement could potentially drive the CD3 ectodomains, situated inside the TCRpMHC-CD4 arch, into the T cell membrane. This in turn could cause displacement of CD3 $\varepsilon$ ITAMs from the membrane and their phosphorylation by Lck.

\section{THE TCR-pMHC-CD4 COMPLEX AND MODELS FOR TCR TRIGGERING}

There is considerable controversy over the mechanism of TCR triggering, and a variety of models have been proposed to explain how pMHC binding to TCR initiates signaling across the T cell membrane (55). Some of these models invoke dimerization (or oligomerization) of CD4 (54), MHC (61), or TCR (57) as a means of enhancing phosphorylation of CD3 ITAMs by increasing the proximity of associated tyrosine kinases. The plausibility of these models can be assessed in terms of the geometrical constraints imposed by the TCR-pMHC-CD4 structure.

The structure of human CD4 D1-D4 in unbound form showed that CD4 molecules form dimers through the D4 domain, at least in the crystal (54). This observation suggested that D4D4-associated CD4 dimers might contribute to $\mathrm{T}$ cell activation by cross-linking TCR-pMHC complexes $(54,62)$. However, the TCR-pMHC-CD4 structure is incompatible with this idea. In a hypothetical model constructed by superposing the TCR-pMHCCD4 structure onto the D4-D4-associated CD4 dimer, the distance between the C-termini of the D4 domains and the T cell surface is too far $(\sim 40 \AA)$ to be spanned by the eight-residue stalk region of CD4 (49). Similarly, the finding that some HLA-DR 

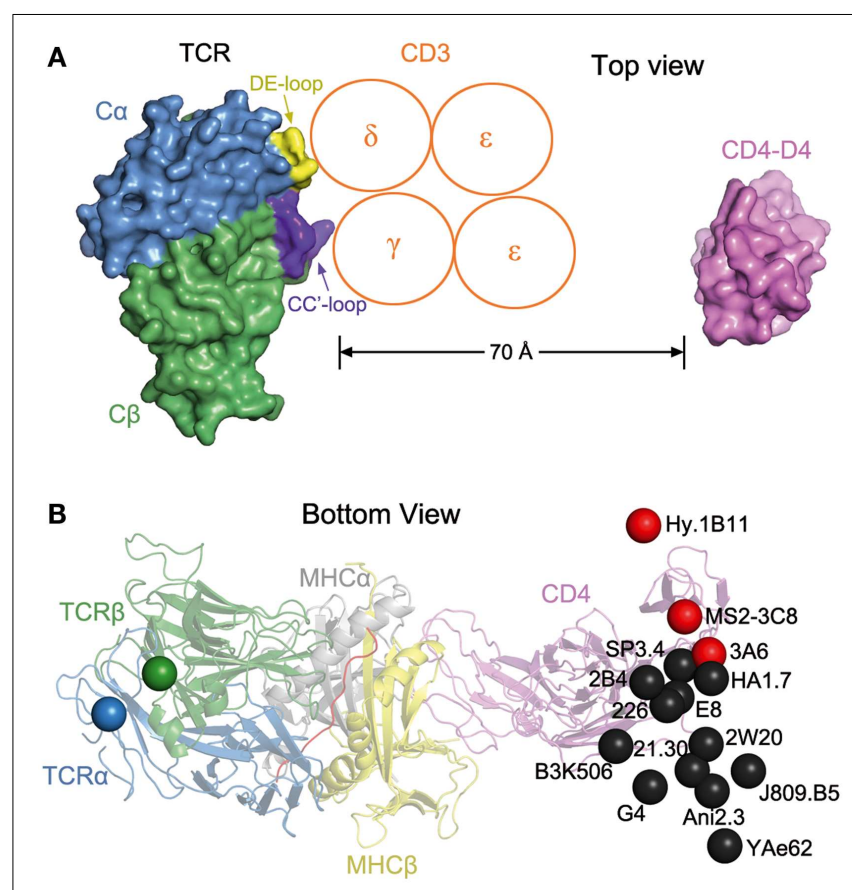

Ob.1A12

FIGURE 4 | Orientation of TCR and CD4 in TCR-pMHC-CD4 complexes (A) Top view of the MS2-3C8-MBP-DR4-CD4 complex (Figure 3A), as if looking down on the T cell. The membrane-proximal TCR $\mathrm{C} \alpha / C \beta$ domains and the CD4 D4 domain are depicted in surface representation. Other domains and pMHC are omitted for clarity. TCR C $\alpha$, blue; TCR C $\beta$, green;

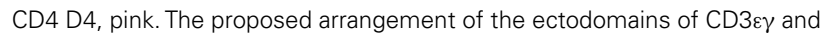
$\mathrm{CD} 3 \varepsilon \delta(58)$ is shown in relation to docking sites identified by mutational analyses $(56,58)$ : $\mathrm{C} \alpha \mathrm{DE}$ loop (yellow) and $\mathrm{C} \beta \mathrm{CC}$ loop (dark blue). The Ig-like ectodomains of $\mathrm{CD} 3 \varepsilon \gamma$ and $\mathrm{CD} 3 \varepsilon \delta$ are drawn as orange circles. In this arrangement, only $\mathrm{CD} 3 \gamma$ and $\mathrm{CD} 3 \delta$ contact the TCR. CD3 $\varepsilon$ projects away from the TCR, toward CD4. (B) Bottom view of the MS2-3C8-MBPDR4-CD4 complex, as if looking up from inside the T cell. On the left side, the C-termini of the extracellular portions of the $\alpha$ and $\beta$ chains of TCR MS2-3C8, as defined in the crystal structure (49), are indicated by blue and green spheres, respectively. On the right side, the C-terminus of the extracellular portion of CD4 in the complex with MS2-3C8 and HLA-DR4 is marked by a red sphere labeled MS2-3C8. The right side also shows the predicted position of the $\mathrm{C}$-terminus of $\mathrm{CD} 4$ in 15 hypothetical ternary complexes constructed using other TCR-pMHC class II structures [human: HA1.7 (1JH8), Ob.1A12 (1YMM), 3A6 (1ZGL), E8 (2IAM), Hy.1B11 (3PL6), G4 (4E41); SP3.4 (4GG6); Ani2.3 (4H1L); mouse: B3K506 (3C5Z), 2W20 (3C6L), YAe62 (3C60), 21.30 (3MBE); J806.B5 (3RDT); 2B4 (3OIB); 226 $(3 \mathrm{OIU})]$. In each case, the C-terminus of CD4 is marked by a colored sphere labeled with the name of the corresponding TCR. Autoimmune TCRs (MS2-3C8, Ob.1A12, 3A6, Hy.1B11) are red; anti-foreign (HA1.7, B3K506, 2W20, 21.30, YAe62, SP3.4, Ani2.3, J805.B5, 2B4, 226) and anti-tumor TCRs $(E 8, G 4)$ are black. The TCR-pMHC-CD4 complexes were modeled by superposing each TCR-pMHC class II structure onto the MS2-3C8-MBPDR4-CD4 complex through the $\mathrm{C} \alpha / \mathrm{C} \beta$ domains of the TCRs. The anti-foreign and anti-tumor TCRs (black spheres) form a cluster that mostly excludes the autoimmune TCRs (red spheres), with Hy.1B11, MS2-3C8, and $3 \mathrm{~A} 6$ on one side of the cluster and Ob.1A12 on the other.

molecules crystallize as dimers $(61,63)$ suggested a mechanism for $\mathrm{T}$ cell triggering in which an MHC class II dimer cross-links two TCRs. However, the CD4-binding site on HLA-DR4 almost completely overlaps the putative HLA-DR dimerization site, which would preclude formation of such MHC class II dimers (49).

Recently, it was proposed that TCRs can dimerize in the $\mathrm{T}$ cell membrane via $\mathrm{C} \alpha-\mathrm{C} \alpha$ interactions, and that the resulting juxtaposition of two TCR-pMHC complexes facilitates signaling through the membrane $(57,64)$. Consistent with this model, the putative site of $\mathrm{C} \alpha-\mathrm{C} \alpha$ dimerization is on the outside of the TCR-pMHC-CD4 arch, opposite the sites mediating TCR-CD3 interactions (Figure 4A) (49). As such, CD4 would not interfere sterically with TCR dimerization through the $\mathrm{C} \alpha$ domain. However, a survey of 22 TCR-pMHC crystal structures failed to reveal any $\mathrm{C} \alpha-\mathrm{C} \alpha$ contacts consistent with biologically relevant TCR dimerization (65). More tellingly, the $\mathrm{C} \alpha$ domain contains two conserved $N$-linked glycans at positions that would preclude the hypothesized TCR dimerization via $\mathrm{C} \alpha-\mathrm{C} \alpha$ interactions.

Several recent studies have demonstrated that physical force applied to the TCR-CD3 complex can activate T cells (66-68). This finding has led to the concept of the TCR as an anisotropic mechanosensor that converts mechanical energy into a biochemical signal upon specific pMHC ligation as a $\mathrm{T}$ cell moves over APCs during immune surveillance (66). While it is unknown how pulling on the TCR-CD3 complex can be transduced to the T cell interior, one possibility is that pMHC binding leads to a conformational change in the CD3 cytoplasmic tails, allowing ITAM phosphorylation by Src kinases. This process may be facilitated by the CD4 (or CD8) co-receptor, whose binding to the TCR-pMHC complex could promote dissociation of CD3 ITAMs from the cytoplasmic side of the T cell membrane and their exposure to Lck, as discussed above.

\section{CO-RECEPTORS AND TCR-pMHC DOCKING ORIENTATION}

The TCR-pMHC-CD4 complex provides a basis for understanding how the CD4 and CD8 co-receptors focus TCR on MHC to guide TCR docking on pMHC during thymic T cell selection. Structural studies of numerous $(>25)$ TCR-pMHC complexes have demonstrated remarkable similarities in the overall topology of TCR binding to pMHC, regardless of MHC class I or class II restriction $(52,53)$. Typically, the TCR is positioned diagonally over the center of the composite surface created by the peptide and the MHC $\alpha$-helices that flank the peptide-binding groove, with $\mathrm{V} \alpha$ situated over the N-terminal half of the peptide, and V $\beta$ over the C-terminal half, although the exact angle and pitch of TCR engagement vary.

Two competing (though not mutually exclusive) hypotheses have been proposed to explain this roughly conserved diagonal binding mode. The first maintains that co-evolution of TCR and MHC genes has led to specific interaction motifs between the germline-encoded CDR1 and CDR2 loops of TCRs and the $\alpha$ helices of MHC proteins (53, 69-73). According to the second hypothesis, TCR docking topology is guided by the CD4 and CD8 co-receptors during $\mathrm{T}$ cell development in order to achieve intracellular juxtaposition of co-receptor-bound Lck with CD3 ITAMs $(11-13,49,71,72,74,75)$. According this view, it is the need for coreceptor function during thymic $\mathrm{T}$ cell selection that restricts the geometry of TCR-pMHC recognition and eliminates from positive selection $\mathrm{CD}^{+}{ }^{+} \mathrm{CD} 8{ }^{+}$double-positive thymocytes expressing 
TCRs unable to engage pMHC in a manner that generates a signal to induce maturation.

The arch-shaped TCR-pMHC-CD4 complex establishes anchor points for TCR and CD4 on the T cell membrane, thereby imposing constraints on the orientation of CD3 relative to Lck associated with CD4 on the cytoplasmic side of the membrane. Figure 4B shows the position of the C-terminus of CD4 observed in the complex with TCR MS2-3C8 and HLA-DR4, as well as the predicted position of the C-terminus of CD4 in hypothetical ternary complexes constructed using 15 other TCR-pMHC class II structures, both human and mouse. Except for the human autoimmune TCR Ob.1A12 (76), the C-termini of CD4 in these modeled complexes are grouped in a loose cluster that includes the C-terminus of CD4 in the MS2-3C8-MBP-DR4-CD4 complex. Differences in the position of the CD4 membrane anchor point are attributable to variations in the diagonal docking topology

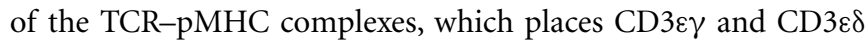
inside the TCR-pMHC-CD4 arch, opposite CD4 (Figure 4A). If the TCR-pMHC docking polarity were reversed (i.e., $\mathrm{V} \alpha$ over the C-terminus of the peptide and $\mathrm{V} \beta$ over the $\mathrm{N}$-terminus), $\mathrm{CD} 3 \varepsilon \gamma$ and $\mathrm{CD} 3 \varepsilon \delta$ would be positioned outside, rather than inside, the TCR-pMHC-CD4 arch. The much greater distance between CD4-bound Lck and CD3 ITAMs would likely hinder ITAM phosphorylation by Lck, thereby preventing positive selection of $\mathrm{T}$ cells bearing TCRs with the reversed polarity, or their activation in the periphery. We therefore propose that the diagonal docking topology of TCR-pMHC complexes reflects not only genetically encoded interactions with $\operatorname{MHC}(53,69)$, but also the requirement to form a ternary complex with the CD4 or CD8 co-receptor that is geometrically competent to deliver a maturation signal to $\mathrm{CD} 4^{+} \mathrm{CD} 8^{+}$thymocytes during $\mathrm{T}$ cell selection.

Nonetheless, some flexibility must exist within the overall signaling complex to accommodate variations in TCR-pMHC docking geometry that affect the location of anchor points for TCR and CD4 on the T cell membrane (Figure 4B). Given the rigidity of the CD4 ectodomain (49), this flexibility most likely resides in interactions involving the flexible cytoplasmic tails of CD3 and CD4 with Lck, which itself can adopt multiple conformations (77). The flexibility of the cytoplasmic domains of CD3 is supported by circular dichroism analysis and disorder prediction algorithms (78). By both methods, the cytoplasmic domains of CD3 $\zeta, \mathrm{CD} 3 \varepsilon, \mathrm{CD} 3 \gamma$, and $\mathrm{CD} 3 \delta$ were found to be intrinsically unstructured, randomcoil proteins in both monomeric and oligomeric states, and in the presence or absence of lipids.

Of the 16 TCRs in Figure 4B, 4 are autoimmune (Hy.1B11, MS2-3C8, 3A6, Ob.1A12). These TCRs, which were isolated from different multiple sclerosis patients, recognize MBP self-peptides bound to HLA-DQ1 (Hy.1B11), HLA-DR4 (MS2-3C8), HLADR2a (3A6), or HLA-DR2b (Ob.1A12). T cells expressing these four autoimmune TCRs escaped negative selection in the thymus yet still retained the ability to productively engage self-antigens in the periphery. The remaining 12 TCRs recognize foreign antigens, such as influenza virus hemagglutinin (HA1.7) and moth cytochrome c $(2 \mathrm{~B} 4,226)$, or tumor antigens $(\mathrm{G} 4, \mathrm{E} 8)$. In Figure 4B, the C-termini of CD4 in the 16 TCR-pMHC-CD4 complexes sweep out an arc of $\sim 70^{\circ}$, with autoimmune TCRs Ob.1A12 and Hy.1B11 at the two extremities. Strikingly, the 12 anti-foreign or tumor-specific TCRs form a relatively tight cluster that effectively excludes the four autoimmune TCRs, with Ob.1A12 on one side of the cluster and Hy.1B11, MS2-3C8, and 3A6 on the other. Because CD4-bound Lck would be positioned differently with respect to CD3 ITAMs inside the T cell, phosphorylation of CD3 ITAMs by Lck may be differentially affected in TCR-pMHC-CD4 complexes involving anti-foreign versus autoimmune TCRs. In this way, the geometry of the TCR-pMHC-CD4 complex could modulate TCR signaling, and thereby directly impact $\mathrm{T}$ cell development and autoimmunity.

\section{IMPLICATIONS FOR THE TCR-pMHC-CD8 TERNARY COMPLEX}

Although no structure of a TCR-pMHC-CD8 ternary complex has been reported, a hypothetical model may be constructed by superposing the $\mathrm{CD} 8 \alpha \beta-\mathrm{H}-2 \mathrm{D}^{\mathrm{d}}$ complex (23) onto a representative TCR-pMHC class I complex through the shared MHC class I molecule (Figure 3B). The model is consistent with the idea that the shorter CD $8 \beta$ stalk helps orient the cytoplasmic domains of $C D 8 \alpha \beta$ for their role in signal transduction $(23,79)$. However, in the absence of structural information on the CD8 stalk, the model cannot establish anchor points for TCR and CD8 on the $\mathrm{T}$ cell membrane, as did the TCR-pMHC-CD4 structure (Figure 3A). While the TCR-pMHC-CD8 complex is probably not as conformationally constrained as the TCR-pMHC-CD4 complex, $\mathrm{O}$-glycosylation of the CD8 stalk likely restricts its flexibility $(36,42)$, as discussed above. By limiting the mobility of the MHC-binding head group of CD8 in this way, O-glycosylation would impose constraints on the orientation of $\mathrm{CD} 3$ subunits relative to CD8-bound Lck, as does the rigid CD4 structure (Figure 4A).

Even with $O$-glycosylation, the proline-rich CD8 stalk is likely to be less stiff than the four tandem Ig-like domains of CD4. This flexibility may help compensate for variations in TCR-pMHC docking geometry to facilitate intracellular juxtaposition of CD8bound Lck with CD3 ITAMs. The cytoplasmic tails of the CD3 subunits would provide additional flexibility within the overall TCRpMHC-CD8 signaling complex, just as in the TCR-pMHC-CD4 complex.

\section{FUTURE DIRECTIONS}

Much more is known about the biophysics of CD8 interactions with TCR-pMHC at the T cell-APC interface than in the case of CD4. For example, whereas in situ studies have demonstrated that TCR and CD8 bind cooperatively to pMHC, and that this synergy amplifies peptide discrimination (9), there is no comparable information for CD4. Conversely, whereas the structure of a TCR-pMHC-CD4 complex has been reported (49), that of a TCR-pMHC-CD8 complex remains to be determined.

Until now, most studies of autoimmunity have emphasized reduced TCR affinity for self-pMHC as the main reason autoreactive $\mathrm{T}$ cells sometimes escape negative selection in the thymus (80). However, it is also possible that the altered docking topologies observed in autoimmune TCR-pMHC complexes (81) may 
modulate $\mathrm{T}$ cell signaling by altering interactions with CD4 or CD8. In fact, autoimmune TCRs appear to segregate from antiforeign TCRs in terms of the geometry of the corresponding TCR-pMHC-CD4 ternary complexes (Figure 4B). This hypothesis clearly merits further investigation, particularly in view of an emerging appreciation for the role of TCR docking geometry on T cell signaling $(49,71)$.

The TCR-pMHC-CD4 structure, in conjunction with mutational data on TCR-CD3 ectodomain interactions, suggests that $\mathrm{CD} 3 \varepsilon \gamma$ and $\mathrm{CD} 3 \varepsilon \delta$ are located under the TCR-pMHC-CD 4 arch, facing CD4 (Figure 4A). However, the current reality is that we only have nebulous ideas about the molecular architecture of

\section{REFERENCES}

1. Janeway CA Jr. The T cell receptor as a multicomponent signalling machine: CD4/CD8 coreceptors and $\mathrm{T}$ cell activation. Annu Rev Immunol (1992) 10:645-54. doi:10. 1146/annurev.immunol.10.1.645

2. Zamoyska R. CD4 and CD8: modulators of T-cell receptor recognition of antigen and of immune responses? Curr Opin Immunol (1998) 10:82-7. doi:10.1016/S09527915(98)80036-8

3. Singer A, Bosselut R. CD4/CD8 coreceptors in thymocyte development, selection, and lineage commitment: analysis of the CD4/CD8 lineage decision. $A d v$ Immunol (2004) 83:91-131. doi: 10.1016/S0065-2776(04)83003-7

4. Laugel B, van den Berg HA, Gostick E, Cole DK, Wooldridge L, Boulter J, et al. Different $\mathrm{T}$ cell receptor affinity thresholds and CD8 coreceptor dependence govern cytotoxic $\mathrm{T}$ lymphocyte activation and tetramer binding properties. $J$ Biol Chem (2007) 282:23799-810. doi: 10.1074/jbc.M700976200

5. Irvine DJ, Purbhoo MA, Krogsgaard M, Davis MM. Direct observation of ligand recognition by $\mathrm{T}$ cells. Nature (2002) 419:845-9. doi:10. 1038 /nature01076

6. Holler PD, Kranz DM. Quantitative analysis of the contribution of TCR/pepMHC affinity and CD8 to $\mathrm{T}$ cell activation. Immunity (2003) 18:255-64. doi:10.1016/ S1074-7613(03)00019-0

7. Li QJ, Dinner AR, Qi S, Irvine DJ, Huppa JB, Davis MM, et al. CD4 enhances $\mathrm{T}$ cell sensitivity to antigen by coordinating Lck accumulation at the immunological synapse. Nat Immunol (2004) 5:791-9. doi: 10.1038/ni1095

8. Artyomov MN, Lis M, Devadas S, Davis MM, Chakraborty AK. CD4 and CD8 binding to MHC molecules primarily acts to enhance Lck delivery. Proc Natl Acad Sci U S A (2010) 107:16916-21. doi:10.1073/ pnas.1010568107

9. Jiang N, Huang J, Edwards LJ, Liu B, Zhang Y, Beal CD, et al. Twostage cooperative $\mathrm{T}$ cell receptorpeptide major histocompatibility complex-CD8 trimolecular interactions amplify antigen discrimination. Immunity (2011) 34:13-23. doi:10.1016/j.immuni.2010.12.017

10. van der Merwe PA, Cordoba SP. Late arrival: recruiting coreceptors to the $\mathrm{T}$ cell receptor complex. Immunity (2011) 34:1-3. doi:10.1016/j. immuni.2011.01.001

11. Van Laethem F, Tikhonova AN, Singer A. MHC restriction is imposed on a diverse $\mathrm{T}$ cell repertoire by CD4 and CD8 co-receptors during thymic selection. Trends Immunol (2012) 33:437-41. doi:10. 1016/j.it.2012.05.006

12. Van Laethem F, Sarafova SD, Park et al. Deletion of CD4 and CD8 coreceptors permits generation of $\alpha \beta T$ cells that recognize antigens independently of the MHC. Immunity (2007) 27:735-50. doi:10.1016/ j.immuni.2007.10.007

13. Tikhonova AN, Van Laethem F, Hanada K, Lu J, Pobezinsky LA, Hong $C$, et al. $\alpha \beta \mathrm{T}$ cell receptors that do not undergo major histocompatibility complex-specific thymic selection possess antibodylike recognition specificities. Immunity (2012) 36:79-81. doi:10.1016/j. immuni.2011.11.013

14. Devine L, Kieffer LJ, Aitken V, Kavathas PB. Human CD8 $\beta$, but not mouse $\mathrm{CD} 8 \beta$, can be expressed in the absence of $\operatorname{CD} 8 \alpha$ as a $\beta \beta$ homodimer. J Immunol (2000) 164:833-8.

15. Cheroutre H, Lambolez F. Doubting the TCR coreceptor function of $\mathrm{CD} 8 \alpha / \alpha$. Immunity (2008) 28:149-56. doi:10.1016/j.immuni. 2008.01.005 JH, Tai X, Pobezinsky L, Guinter TI, the TCR-CD3 complex. Direct structural analysis of the TCR$\mathrm{CD} 3$ complex will be required to establish anchor points for CD3 and CD4 on the T cell membrane. This information, combined with the known pairings of the transmembrane helices of the TCR and CD3 chains from mutational analysis $(\mathrm{TCR} \alpha-\mathrm{CD} 3 \varepsilon \delta$, $\mathrm{TCR} \alpha-\mathrm{CD} 3 \zeta \zeta$, and TCR $\beta-\mathrm{CD} 3 \varepsilon \gamma$ ) (59), will reveal the intracellular organization of CD3 ITAMs relative to each other, and relative to Lck bound to the $\mathrm{CD} 4$ or $\mathrm{CD} 8$ co-receptor.

\section{ACKNOWLEDGMENTS}

This work was supported by Grants from the National Institutes of Health (AI036900 and AI073654) to Roy A. Mariuzza.
16. Fung-Leung WP, Schilham MW, Rahemtulla A, Kündig TM, Vollenweider M, Potter J, et al. CD8 is needed for development of cytotoxic $\mathrm{T}$ cells but not helper T cells. Cell (1991) 65:443-9. doi:10.1016/ 0092-8674(91)90462-8

17. Crooks ME, Littman DR. Disruption of $\mathrm{T}$ lymphocyte positive and negative selection in mice lacking the CD8 $\beta$ chain. Immunity (1994) 1:277-85. doi:10.1016/10747613(94)90079-5

18. Nakayama K, Negishi I, Kuida $\mathrm{K}$, Louie MC, Kanagawa O, Nakauchi $H$, et al. Requirement for CD8 $\beta$ chain in positive selection of CD8-lineage $\mathrm{T}$ cells. Science (1994) 263:1131-3. doi: 10.1126/science.8108731

19. Moebius U, Kober G, Griscelli AL, Hercend T, Meuer SC. Expression of different CD8 isoforms on distinct human lymphocyte subpopulations. Eur J Immunol (1991) 21:1793-800. doi:10.1002/ eji.1830210803

20. Grebe KM, Clarke RL, Potter TA. Ligation of CD8 leads to apoptosis of thymocytes that have not undergone positive selection. Proc Natl Acad Sci $U S A$ (2004) 101:10410-5. doi:10.1073/ pnas.0402079101

21. Yachi PP, Ampudia J, Zal T, Gascoigne NR. Altered peptide ligands induce delayed CD8-T cell receptor interaction - a role for CD8 in distinguishing antigen quality. Immunity (2006) 25:203-11. doi: 10.1016/j.immuni.2006.05.015

22. Garcia KC, Scott CA Brunmark A, Carbone FR, Peterson PA, Wilson IA, et al. CD8 enhances formation of stable T-cell receptor/MHC class I molecule complexes. Nature (1996) 384:577-81. doi:10.1038/384577a0

23. Wang R, Natarajan K, Margulies DH. Structural basis of the CD8 $\alpha \beta / \mathrm{MHC}$ class I interaction: focused recognition orients CD8 $\beta$ to a $\mathrm{T}$ cell proximal position. I Immunol (2009) 183:2554-64. doi:10.4049/ jimmunol.0901276

24. Wyer JR, Willcox BE, Gao GF, Gerth UC, Davis SJ, Bell JI, et al. T cell receptor and coreceptor CD8 $\alpha \alpha$ bind peptide-MHC independently and with distinct kinetics. Immunity (1999) 10:219-25. doi:10.1016/ S1074-7613(00)80022-9

25. Gao GF, Willcox BE, Wyer JR, Boulter JM, O'Callaghan CA, Maenaka $\mathrm{K}$, et al. Classical and nonclassical class I major histocompatibility complex molecules exhibit subtle conformational differences that affect binding to CD $8 \alpha \alpha$. J Biol Chem (2000) 275:15232-8. doi: 10.1074/jbc.M909946199

26. Cole DK, Dunn SM, Sami M, Boulter JM, Jakobsen BK, Sewell AK. T cell receptor engagement of peptide-major histocompatibility complex class I does not modify CD8 binding. Mol Immunol (2008) 45:2700-9. doi:10.1016/j.molimm. 2007.12.009

27. Huang J, Edwards LJ, Evavold BD, Zhu C. Kinetics of MHC-CD8 interaction at the $\mathrm{T}$ cell membrane. J Immunol (2007) 179:7653-62.

28. Zhu C, Jiang N, Huang J, Zarnitsyna VI, Evavold BD. Insights from in situ analysis of TCR-pMHC recognition: response of an interaction network. Immunol Rev (2013) 251:49-64. doi:10.1111/imr.12016

29. Gao GF, Tormo J, Gerth UC, Wyer JR, McMichael AJ, Stuart DI, et al. Crystal structure of the complex between human CD8 $\alpha \alpha$ and HLAA2. Nature (1997) 387:630-4. doi: $10.1038 / 42523$

30. Shi Y, Qi J, Iwamoto A, Gao GF Plasticity of human CD8 $\alpha \alpha$ binding to peptide-HLA-A*2402. $\mathrm{Mol}$ Immunol (2011) 48:2198-202. doi: 10.1016/j.molimm.2011.05.009 
31. Kern PS, Teng MK, Smolyar A, Liu JH, Liu J, Hussey RE, et al. Structural basis of CD8 coreceptor function revealed by crystallographic analysis of a murine CD8 $\alpha \alpha$ ectodomain fragment in complex with $\mathrm{H}-2 \mathrm{~K}^{\mathrm{b}}$. Immunity (1998) 9:519-30. doi:10. 1016/S1074-7613(00)80635-4

32. Casabó LG, Mamalaki C, Kioussis D, Zamoyska R. T cell activation results in physical modification of the mouse CD8 $\beta$ chain. J Immunol (1994) 152:397-404.

33. Rudd PM, Elliott T, Cresswell P, Wilson IA, Dwek RA. Glycosylation and the immune system. Science (2001) 291:2370-6. doi:10. 1126/science.291.5512.2370

34. Moody AM, Chui D, Reche PA, Priatel JJ, Marth JD, Reinherz EL. Developmentally regulated glycosylation of the CD $8 \alpha \beta$ coreceptor stalk modulates ligand binding. Cell (2001) 107:501-12. doi: 10.1016/S0092-8674(01)00577-3

35. Daniels MA, Devine L, Miller JD, Moser JM, Lukacher AE, Altman $\mathrm{JD}$, et al. CD8 binding to MHC class I molecules is influenced by $\mathrm{T}$ cell maturation and glycosylation. Immunity (2001) 15:1051-61. doi: 10.1016/S1074-7613(01)00252-7

36. Merry AH, Gilbert RJ, Shore DA, Royle L, Miroshnychenko O, Vuong $\mathrm{M}$, et al. O-glycan sialylation and the structure of the stalk-like region of the T cell co-receptor CD8. J Biol Chem (2003) 278:27119-28. doi:10. 1074/jbc.M213056200

37. Santos SG, Powis SJ, Arosa FA. Misfolding of major histocompatibility complex class I molecules in activated $\mathrm{T}$ cells allows cis-interactions with receptors and signaling molecules and is associated with tyrosine phosphorylation. J Biol Chem (2004) 279:53062-70. doi:10.1074/ jbc.M408794200

38. Back J, Malchiodi EL, Cho S, Scarpellino L, Schneider P, Kerzic $\mathrm{MC}$, et al. Distinct conformations of Ly49 natural killer cell receptors mediate MHC class I recognition in trans and cis. Immunity (2009) 31:598-608. doi:10.1016/j.immuni. 2009.07.007

39. Hartmann J, Tran TV, Kaudeer J, Oberle K, Herrmann J, Quagliano I, et al. The stalk domain and the glycosylation status of the activating natural killer cell receptor NKp30 are important for ligand binding. J Biol Chem (2012) 287:31527-39. doi:10.1074/jbc.M111.304238

40. Shogren R, Gerken TA, Jentoft N. Role of glycosylation on the conformation and chain dimensions of $\mathrm{O}$-linked glycoproteins: light scattering studies of ovine submaxillary mucin. Biochemistry (1989) 28:5525-36. doi:10.1021/ bi00439a029

41. Gerken TA, Butenhof JK, Shogren R. Effects of glycosylation on the conformation and dynamics of O-linked glycoproteins: carbon-13 NMR studies of ovine submaxillary mucin. Biochemistry (1989) 28:5536-43. doi: 10.1021/bi00439a030

42. Shore DA, Wilson IA, Dwek RA, Rudd PM. Glycosylation and the function of the $\mathrm{T}$ cell coreceptor CD8. Adv Exp Med Biol (2005) 564:71-84. doi:10.1007/0387-25515-X_12

43. Davis SJ, Ikemizu S, Evans EJ, Fugger L, Bakker TR, van der Merwe PA. The nature of molecular recognition by T cells. Nat Immunol (2003) 4:217-24. doi:10.1038/ni0303-217

44. Cole DK, Pumphrey NJ, Boulter JM, Sami M, Bell JI, Gostick E, et al. Human TCR-binding affinity is governed by MHC class restriction. J Immunol (2007) 178:5727-34.

45. Xiong Y, Kern P, Chang H, Reinherz E. T cell receptor binding to a pMHCII ligand is kinetically distinct from and independent of CD4. J Biol Chem (2001) 276:5659-67. doi:10.1074/jbc.M009580200

46. Robinson J, Mistry K, McWilloam H, Lopez R, Parham P, Marsh SGE. The IMGT/HLA database. Nucleic Acids Res (2011) 39:D1171-6. doi: 10.1093/nar/gkq998

47. Wang JH, Meijers R, Xiong Y, Liu JH, Sakihama T, Zhang R, et al. Crystal structure of the human CD4 $\mathrm{N}$-terminal two-domain fragment complexed to a class II MHC molecule. Proc Natl Acad Sci U S A (2001) 98:10799-804. doi:10.1073/ pnas.191124098

48. Wang XX, Li Y, Yin Y, Mo M, Wang $\mathrm{Q}$, Gao W, et al. Affinity maturation of human CD4 by yeast surface display and crystal structure of a CD4HLA-DR1 complex. Proc Natl Acad Sci U S A (2011) 108:15960-5. doi: 10.1073/pnas.1109438108

49. Yin Y, Wang XX, Mariuzza RA. Crystal structure of a complete ternary complex of T-cell receptor, peptideMHC, and CD4. Proc Natl Acad Sci U S A (2012) 109:5405-10. doi: 10.1073/pnas.1118801109

50. Gai SA, Wittrup KD. Yeast surface display for protein engineering and characterization. Curr Opin Struct Biol (2007) 17:467-73. doi:10.1016/ j.sbi.2007.08.012

51. Yin Y, Li Y, Kerzic MC, Martin R, Mariuzza RA. Structure of a TCR with high affinity for self-antigen reveals basis for escape from negative selection. $E M B O$ $J$ (2011) 30:1137-48. doi:10.1038/ emboj.2011.21

52. Rudolph MG, Stanfield RL, Wilson IA. How TCRs bind MHCs, peptides, and coreceptors. Annu Rev Immunol (2006) 24:419-66. doi:10.1146/annurev.immunol.23. 021704.115658

53. Marrack P, Scott-Browne JP, Dai S, Gapin L, Kappler JW. Evolutionarily conserved amino acids that control TCR-MHC interaction. Annu Rev Immunol (2008) 26:171-203. doi:10.1146/annurev. immunol.26.021607.090421

54. Wu H, Kwong PD, Hendrickson WA. Dimeric association and segmental variability in the structure of human CD4. Nature (1997) 387:527-30. doi:10.1038/387527a0

55. van der Merwe PA, Dushek O. Mechanisms of T cell receptor triggering. Nat Rev Immunol (2010) 11:47-55. doi:10.1038/nri2887

56. Kuhns MS, Davis MM. Disruption of extracellular interactions impairs $\mathrm{T}$ cell receptor-CD3 complex stability and signaling. Immunity (2007) 26:357-69. doi:10.1016/ j.immuni.2007.01.015

57. Kuhns MS, Girvin AT, Klein LO, Chen R, Jensen KD, Newell EW, et al. Evidence for a functional sidedness to the $\alpha \beta$ TCR. Proc Natl Acad Sci U S A (2010) 107:5094-9. doi: 10.1073/pnas. 1000925107

58. Fernandes RA, Shore DA, Vuong MT, Yu C, Zhu X, Pereira-Lopes S, et al. The T-cell receptor is a structure capable of initiating signaling in the absence of large conformational rearrangements. J Biol Chem (2012) 287:13324-35. doi:10.1074/ jbc.M111.332783

59. Call ME, Pyrdol J, Wiedmann M, Wucherpfennig KW. The organizing principle in the formation of the $\mathrm{T}$ cell receptor-CD3 complex. Cell (2002) 111:967-79. doi:10. 1016/S0092-8674(02)01194-7

60. Xu C, Gagnon E, Call ME, Schnell JR, Schwieters CD, Carman CV, et al. Regulation of $\mathrm{T}$ cell receptor activation by dynamic membrane binding of the CD $3 \varepsilon$ cytoplasmic tyrosinebased motif. Cell (2008) 135:70213. doi:10.1016/j.cell.2008.09.044

61. Brown JH, Jardetzky TS, Gorga JC, Stern LJ, Urban RG, Strominger JL, et al. Three-dimensional structure of the human class II histocompatibility antigen HLA-DR1. Nature (1993) 364:33-9. doi:10. 1038/364033a0

62. Moldovan MC, Sabbagh L, Breton G, Sékaly RP, Krummel MF.
Triggering of $\mathrm{T}$ cell activation via CD4 dimers. J Immunol (2006) 176:5438-45.

63. Ghosh P, Amaya M, Mellins E, Wiley DC. The structure of an intermediate in class II MHC maturation: CLIP bound to HLA-DR3. Nature (1995) 378:457-62. doi:10. 1038/378457a0

64. Kuhns MS, Badgandi HB. Piecing together the family portrait of TCR-CD3 complexes. Immunol Rev (2012) 250:120-43. doi:10. 1111/imr. 12000

65. Wang JH, Reinherz EL. Revisiting the putative TCR $\mathrm{C} \alpha$ dimerization model through structural analysis. Front Immunol (2013) 4:16. doi: 10.3389/fimmu.2013.00016

66. Kim ST, Takeuchi K, Sun ZY, Touma M, Castro CE, Fahmy A, et al. The $\alpha \beta \mathrm{T}$ cell receptor is an anisotropic mechanosensor. $\mathrm{J} \mathrm{Biol}$ Chem (2009) 284:31028-37. doi:10. 1074/jbc.M109.052712

67. Li YC, Chen BM, Wu PC, Cheng TL, Kao LS, Tao MH, et al. Cutting edge: mechanical forces acting on T cells immobilized via the TCR complex can trigger TCR signaling. Jimmunol (2010) 184:5959-63. doi: 10.4049/jimmunol.0900775

68. Judokusumo E, Tabdanov E, Kumari S, Dustin ML, Kam LC. Mechanosensing in $\mathrm{T}$ lymphocyte activation. Biophys J (2012) 102:L5-7. doi: 10.1016/j.bpj.2011.12.011

69. Garcia KC, Adams JJ, Feng D, Ely LK. The molecular basis of TCR germline bias for MHC is surprisingly simple. Nat Immunol (2009) 10:143-7. doi: 10.1038/ni.f.219

70. Scott-Browne JP, White J, Kappler JW, Gapin L, Marrack P. Germlineencoded amino acids in the $\alpha \beta$ T-cell receptor control thymic selection. Nature (2009) 458:1043-6. doi:10. 1038/nature07812

71. Adams JJ, Narayanan S, Liu B, Birnbaum ME, Kruse AC, Bowerman $\mathrm{NA}$, et al. T cell receptor signaling is limited by docking geometry to peptide-major histocompatibility complex. Immunity (2011) 35:68193. doi:10.1016/j.immuni.2011.09. 013

72. Garcia KC. Reconciling views on $\mathrm{T}$ cell receptor germline bias for MHC. Trends Immunol (2012) 33:429-36. doi:10.1016/j.it.2012.05. 005

73. Deng L, Langley RJ, Wang Q, Topalian SL, Mariuzza RA. Structural insights into the editing of germ-line-encoded interactions between $\mathrm{T}$-cell receptor and $\mathrm{MHC}$ 
class II by V $\alpha$ CDR3. Proc Natl Acad Sci U S A (2012) 109:14960-5. doi: 10.1073/pnas.1207186109

74. Buslepp J, Wang H, Biddison WE, Appella E, Collins EJ. A correlation between TCR $\mathrm{V} \alpha$ docking on MHC and CD8 dependence: implications for $\mathrm{T}$ cell selection. Immunity (2003) 19:595-606. doi: 10.1016/S1074-7613(03)00269-3

75. Mazza C, Malissen B. What guides MHC-restricted TCR recognition? Semin Immunol (2007) 19: 225-35. doi:10.1016/j.smim.2007. 03.003

76. Hahn M, Nicholson MJ, Pyrdol J, Wucherpfennig KW. Unconventional topology of self peptidemajor histocompatibility complex binding by a human autoimmune
T cell receptor. Nat Immunol (2005) 6:490-6. doi:10.1038/ni1187

77. Boggon TJ, Eck MJ. Structure and regulation of Src family kinases. Oncogene (2004) 23:7918-27. doi: 10.1038/sj.onc. 1208081

78. Sigalov AB, Aivazian DA, Uversky VN, Stern LJ. Lipid-binding activity of intrinsically unstructured cytoplasmic domains of multichain immune recognition receptor signaling subunits. Biochemistry (2006) 45:15731-9. doi:10. 1021/bi061108f

79. Rettig LL, McNeill L, Sarner N, Guillaume P, Luescher I, Tolaini M, et al. An essential role for the stalk region of $\mathrm{CD} 8 \beta$ in the coreceptor function of CD8. J Immunol (2009) 182:121-9.
80. Goodnow CC, Sprent J, Fazekas de St Groth B, Vinuesa CG. Cellular and genetic mechanisms of self tolerance and autoimmunity. Nature (2005) 435:590-7. doi:10. 1038/nature03724

81. Wucherpfennig KW, Call MJ, Deng L, Mariuzza RA. Structural alterations in peptide-MHC recognition by self-reactive T cell receptors. Curr Opin Immunol (2009) 21:590-5. doi:10.1016/j.coi.2009.07.008

Conflict of Interest Statement: The authors declare that the research was conducted in the absence of any commercial or financial relationships that could be construed as a potential conflict of interest.
Received: 07 May 2013; paper pending published: 30 May 2013; accepted: 08 July 2013; published online: 22 July 2013. Citation: Li Y, Yin Y and Mariuzza $R A$ (2013) Structural and biophysical insights into the role of CD4 and CD8 in T cell activation. Front. Immunol. 4:206. doi: 10.3389/fimmu.2013.00206

This article was submitted to Frontiers in $T$ Cell Biology, a specialty of Frontiers in Immunology.

Copyright (c) 2013 Li, Yin and Mariuzza. This is an open-access article distributed under the terms of the Creative Commons Attribution License, which permits use, distribution and reproduction in other forums, provided the original authors and source are credited and subject to any copyright notices concerning any third-party graphics etc. 